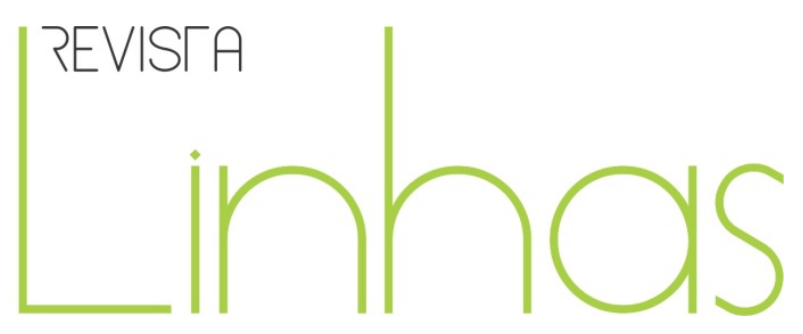

\title{
Moderno, Modernidade e Modernização: a educação nos projetos de Brasil - séculos XIX e XX
}

GIL, Natália; ZICA, Matheus da Cruz; FARIA FILHO, Luciano Mendes de (Org.). Moderno, Modernidade e Modernização: a educação nos projetos de Brasil - séculos XIX e XX. Belo Horizonte: Mazza Edições, 2012.

\author{
Hiassana Scaravelli \\ Graduanda do Curso de Pedagogia da \\ Universidade do Estado de Santa Catarina - UDESC \\ hiassana@yahoo.com
}

Sélia Ana Zonin

Graduanda do Curso de Pedagogia da Universidade do Estado de Santa Catarina - UDESC

anaselia84@hotmail.com

\section{Para citar esta resenha:}

SCARAVELLI, Hiassana; ZONIN, Sélia Ana. Moderno, Modernidade e Modernização: a educação nos projetos de Brasil - séculos XIX e XX. Revista Linhas, Florianópolis, v. 15, n. 28, p. 412-417, jan./jun. 2014.

DOI: $10.5965 / 1984723815282014412$

http://dx.doi.org/10.5965/1984723815282014412 
O livro aqui resenhado é resultado de pesquisas desenvolvidas durante a primeira fase do Projeto “Moderno, modernidade e modernização: a educação nos projetos de Brasil - séculos XIX e XX" e foi publicado em 2012. Por se tratar de um projeto de amplitude nacional, nesta obra encontramos artigos de pesquisadores da Universidade Federal do Rio Grande do Sul (UFRGS), Universidade Federal Fluminense (UFF), Universidade Federal de Santa Catarina (UFSC) e Universidade Federal de Minas Gerais (UFMG), esta com o maior número de representantes. A formação dos autores perpassa diferentes níveis, indo desde a iniciação científica, passando por mestrandos e mestres, doutorandos e doutores, até pós-doutores. Quanto às produções, verifica-se que a predominância da escrita se dá individualmente, com exceção de um dos artigos escrito em parceria.

Esta publicação faz parte da Coleção Cinco Séries, inserida na Série Estudos Históricos, que divulga trabalhos acerca da História da Educação e outras áreas do campo educativo que favorecem a discussão a respeito do lugar da educação nos projetos de Brasil. A Coleção Cinco Séries, por sua vez, integra-se ao Projeto "Pensar a Educação Pensar o Brasil (1822-2022)" coordenado por Luciano Mendes de Faria Filho e Tarcísio Mauro Vago desenvolvido na Faculdade de Educação da Universidade Federal de Minas Gerais.

O livro Moderno, Modernidade e Modernização: a educação nos projetos de Brasil séculos XIX e XX organizado por Natália Gil (UFRGS), Matheus da Cruz e Zica (UFPB) e Luciano Mendes de Faria Filho (UFMG) é composto por onze artigos. Por se tratar de uma coletânea de artigos e levando-se em consideração os limites que configuram a escrita de uma resenha, optamos por não apresentar cada artigo individualmente, mas mostrar ao leitor os principais conceitos, fontes, recortes temporais e referenciais teóricos mobilizados nesta obra.

\section{Conceitos}

O fio que amarra as discussões dos artigos refere-se especialmente aos conceitos de moderno, modernidade e modernização, relacionados a questões ligadas à educação 
em diferentes espaços e tempos. Os projetos de Brasil vinculados a uma educação moderna se dão em meio a discursos ligados às questões políticas, econômicas, sociais, culturais e educacionais, predominantemente em esferas públicas, sob a justificativa de superar o atraso e contribuir com práticas que favorecessem o desenvolvimento e o progresso da Nação. Frente a isso, a educação, naquela época era vista como um mecanismo de transformação social e, portanto, era necessária uma reorganização do sistema de ensino público, a ampliação de escolas, novos e modernos métodos pedagógicos, baseados com frequência em modelos internacionais (Estados Unidos e Europa). Alguns dos artigos também abordam a questão da perspectiva dos intelectuais, analisando diferentes personalidades envolvidas com questões educacionais em ambientes e configurações históricas diversas, como Lourenço Filho, Almeida Junior, Bernardo Guimarães, Monteiro Lobato, Henrique Fontes, Oswaldo Cabral, Sivio Coelho dos Santos, Álvaro Vieira Pinto e Anísio Teixeira. Outros conceitos como ideário moderno, identidade nacional, instrução, dualismos do tipo velho/novo; atraso/progresso; rural/urbano; arcaico/moderno são recorrentes ao longo dos textos.

\section{Principais Fontes}

No que diz respeito aos documentos utilizados pelos autores como fontes, observamos que elas perpassam documentos impressos nas mais variadas formas: desde publicações, escritos, impressos, livros e artigos de educação; imprensa: jornalística e de revista; livros didáticos; documentos oficiais e curriculares (provas, exames, programas de ensino, manuais e compêndios, relatórios e regulamentos) até poemas e verbetes de dicionários.

\section{Recorte Temporal}

As produções abarcam a análise de um recorte temporal que corresponde a diferentes décadas dos séculos XIX e XX. Sobre o século XIX encontramos dois artigos. São eles: "De honra da família à honra da pátria: modernidade e masculinidade 
oitocentistas na escrita de Bernardo Guimarães" de Matheus da Cruz e Zica e "Os conteúdos da matéria de Pedagogia nas Escolas Normais mineiras do final do século XIX: ideias do moderno e da modernidade" de Deolinda Armani Turci. Os que se detém na análise de períodos relativos ao século XX totalizam sete artigos. São eles: "Excelência escolar, decisões políticas e as estatísticas de educação” de Natália Gil; “O Brasil para estrangeiro ler: livros sobre o Brasil na Biblioteca Nacional de Maestros de Buenos Aires” de Luciano Mendes de Faria Filho e Bruna Marinho Valle Roriz; "Os Pedrinhos de Monteiro Lobato e Lourenço Filho: a criança e o Brasil em projetos de modernidade para a nação" de Raquel de Abreu; "Ideário pedagógico moderno nos discursos dos intelectuais Henrique Fontes e Oswaldo Cabral: escola primária catarinense" de Solange Aparecida de Oliveira Hoeller; “Educação e modernização no pensamento de Sílvio Coelho dos Santos em Santa Catarina na década de 1960" de Marilândes Mól Ribeiro de Melo; “Desenvolvimento e políticas educativas no Brasil nos anos 1950 - 1960: transnacionalização e modernização" de Maria das Dores Daros e "A educação no debate do desenvolvimento: as décadas de 1950 e 1960" de Maria do Carmo Xavier. Há, ainda, um que analisa as décadas finais do século XIX avançando para os primeiros anos do século XX, como é o caso do artigo "Imprensa e modernidade: algumas considerações em torno dos anúncios de jornal” de Raquel Menezes Pacheco. Já o primeiro artigo intitulado “Moderno, modernidade, modernização: polissemias e pregnâncias”, de Marcus Vinicius Corrêa Carvalho, não se delimita a um período específico, mas faz um panorama histórico do surgimento dos conceitos, bem como algumas discussões sobre as diversas apropriações e aplicações destes.

\section{Referenciais Teóricos}

Entre os diversos autores referenciados nos textos, evidenciamos a predominância de alguns, como: Jacques Le Goff, com as obras Antigo/Moderno, História e memória, Na Idade Média: tempo da Igreja e tempo mercador; Roger Chatier com História cultural: entre práticas e representações, Inscrever e apagar: cultura escrita e literatura, séculos XI-XVIII e O mundo como representação; Alain Desrosiéres com a obra Entre a ciência universal e as 
tradições nacionais; Luciano Mendes de Faria Filho com o trabalho A legislação escolar como fonte para a História da Educação: uma tentativa de interpretação, e as demais publicações escritas em parcerias: Educação e modernidade: a estatística como estratégia de conformação do campo pedagógico Brasileiro, Os tempos e espaços escolares no processo de institucionalização da escola primária no Brasil, Os projetos de Brasis e a questão da instituição no nascimento do Império, A estatística educacional e a instrução pública no Brasil: aproximações, "A história da feminização do magistério no Brasil: balanço e perspectiva de pesquisas"; Michel de Certeau com os livros A invenção do cotidiano 1: artes de fazer e A escrita da história; Lucien Febvre também com os seus livros Honra e Pátria e Combates pela História I e Marta M. Chagas Carvalho com as obras A escola e a República e outros ensaios e Molde nacional e fôrma física: higiene, moral e trabalho no projeto da Associação Brasileira de Educação (1924 - 1931) e com os trabalhos Reformas da instrução pública, A caixa de utensílios e a biblioteca: Pedagogia e prática de leitura e Modernidade pedagógica e modelos de formação docente.

\section{Considerações}

As noções de moderno, modernidade e modernização presentes no livro nos permitem compreender que existem diferentes apropriações destes termos, que por sua vez possibilitaram reflexões e conhecimentos acerca da construção e transformação das práticas e discursos que permearam a Educação Pública.

A leitura do conjunto de artigos desafia pelas diferentes possibilidades que apontam, desestabiliza pela crítica a conceitos e formas de análise, instiga o leitor a investimentos que levem a, como sugerem os organizadores, "uma reflexão refinada sobre as diversas práticas e discursos que perpassaram a temática da Educação Pública nas diferentes conjunturas históricas de nossa trajetória nacional” (p. 7). 
Recebido em: 15/04/2014 Aprovado em: 03/05/2014

Universidade do Estado de Santa Catarina - UDESC Programa de Pós-Graduação em Educação - PPGE

Revista Linhas

Volume 15 - Número 28 - Ano 2014 revistalinhas@gmail.com 